University of Warwick institutional repository: http://go.warwick.ac.uk/wrap This paper is made available online in accordance with publisher policies. Please scroll down to view the document itself. Please refer to the repository record for this item and our policy information available from the repository home page for further information.

To see the final version of this paper please visit the publisher's website. Access to the published version may require a subscription.

Author(s): Martha R.J. Clokie, Andrew D. Millard, Jaytry Y. Mehta and Nicholas H. Mann

Article Title: Virus isolation studies suggest short-term variations in abundance in natural cyanophage populations of the Indian Ocean Year of publication: 2006 Link to published version: http://dx.doi.org/ 10.1017/S0025315406013403 Publisher statement: None 


\title{
Virus isolation studies suggest short-term variations in abundance in natural cyanophage populations of the Indian Ocean
}

\author{
Martha R.J. Clokie*, Andrew D. Millard*, Jaytry Y. Mehta and Nicholas H. Mann \\ Department of Biological Sciences, University of Warwick, Coventry, GV4 7AL, UK. \\ *Joint first authorship and corresponding authors, e-mail: martha.clokie@warwick.ac.uk \\ and a.d.millard@warwick.ac.uk
}

\begin{abstract}
Gyanophage abundance has been shown to fluctuate over long timescales and with depth, but little is known about how it varies over short timescales. Previous short-term studies have relied on counting total virus numbers and therefore the phages which infect cyanobacteria cannot be distinguished from the total count.

In this study, an isolation-based approach was used to determine cyanophage abundance from water samples collected over a depth profile for a $24 \mathrm{~h}$ period from the Indian Ocean. Samples were used to infect Synechococcus sp. WH7803 and the number of plaque forming units (pfu) at each time point and depth were counted. At $10 \mathrm{~m}$ phage numbers were similar for most time-points, but there was a distinct peak in abundance at 0100 hours. Phage numbers were lower at $25 \mathrm{~m}$ and $50 \mathrm{~m}$ and did not show such strong temporal variation. No phages were found below this depth. Therefore, we conclude that only the abundance of phages in surface waters showed a clear temporal pattern over a short timescale. Fifty phages from a range of depths and time points were isolated and purified. The molecular diversity of these phages was estimated using a section of the phage-encoded $p s b D$ gene and the results from a phylogenetic analysis do not suggest that phages from the deeper waters form a distinct subgroup.
\end{abstract}

\section{INTRODUCTION}

Unicellular cyanobacteria of the genera Synechococcus and Prochlorococcus dominate the prokaryotic component of the marine picophytoplankton, contributing between $32 \%$ and $89 \%$ of primary production in the open ocean (Goericke \& Welschmeyer, 1993; Liu et al., 1997). Factors which control cyanobacterial primary production include nutrient limitation, photosynthetically available radiation, grazers and phages (e.g. Suttle, 2005). High concentrations of viral particles are a ubiquitous and dynamic component of marine ecosystems (e.g. Bergh et al., 1989). Recent studies have shown that the abundance and genetic diversity of marine bacteriophages and Synechococcus are correlated (Weinbauer \& Rassoulzadegan, 2004; Mühling et al., 2005). Because changes in abundance and diversity occur in the bacteriophage community before they occur in the Synechococcus community, it seems that that they drive the dynamics of the host rather than just respond to it (e.g. Weinbauer \& Rassoulzadegan, 2004; Mühling et al., 2005).

It has been suggested for Synechococcus that the periodicity of viral infection and lysis varies during the diel cycle (Suttle, 2000a). This is also thought to be the case with heterotrophic bacteria and their viral hosts (e.g. Winter et al., 2004). The theory proposed by these authors is that phage infection reaches a maximum during daylight hours when maximum bacterial activity occurs. Because phages rely on energy to replicate and assemble from their hosts, it seems logical that these processes occur when their hosts are most metabolically active. This would increase the total number of phage progeny created. Phages are damaged by UV light, which decreases with the diminishing daylight, and so it is suggested that the maximum number of undamaged phages are then available for host infection towards nightfall (Winter et al., 2004). This simple scenario is complicated in Synechococcus in view of recent knowledge that some cyanobacterial phages cannot infect their hosts in the dark (Ying Jia, personal communication).

A further intriguing component of the relationship between Synechococcus and their phages is the discovery of photosynthesis genes $p s b A$ and $p s b D$ in the genomes of phage which infect Synechococcus (Mann, 2003; Millard et al., 2004; Mann et al., 2005). These genes encode the D1 and D2 proteins that are key components of the photosynthetic reaction centre photosystem II (PSII). D1 and D2 form a heterodimer at the heart of the PSII where they bind the pigments and cofactors that are needed for primary photochemistry. These proteins are very susceptible to light damage and thus the genes encoding them are strongly expressed by cyanobacteria during daylight hours to maintain photosystem function (Gill et al., 2002). Indeed, failure to repair the damaged photosystem results in no photosynthesis (photoinhibition). It has been shown that D1 and, to a lesser extent, D2 are some of the most rapidly turned over proteins in a healthy cyanobacterial cell (Bailey et al., 2002). The phage-encoded versions of $p s b A$ and $p s b D$ have been shown to be expressed during the infection cycle (Clokie et al., 2006). As the host 


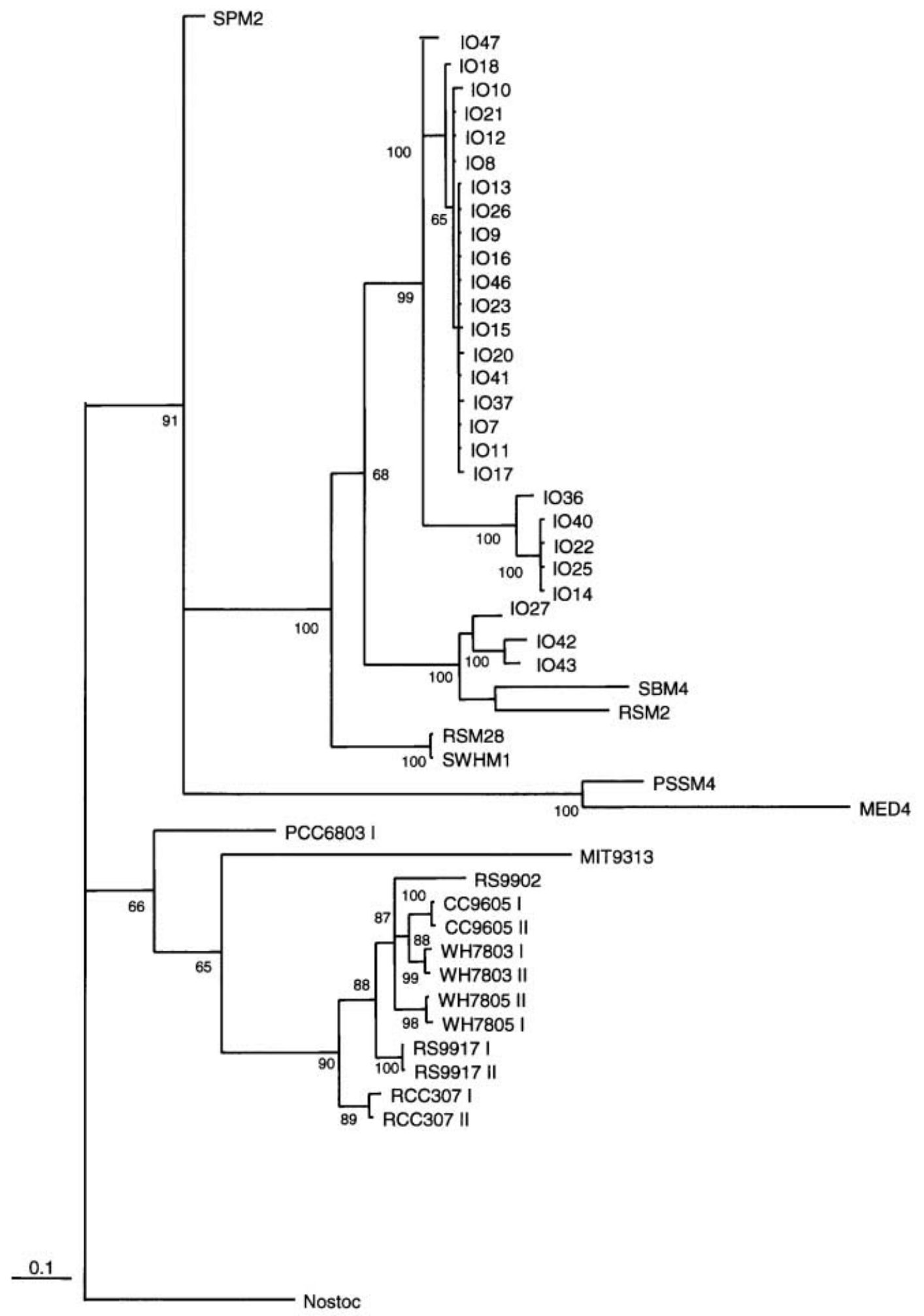

Figure 1. Phylogenetic analysis using MRBAYES of the psb D gene from 27 newly isolated Synechococcus viruses: IO7 (DQ410696), IO8 (DQ410697), IO9 (DQ410671), IO10 (DQ410672), IO11 (DQ410684), IO12 (DQ410685), IO13 (DQ410686), IO14 (DQ410687), IO15 (DQ410673), IO16 (DQ410674), IO17 (DQ410688), IO18 (DQ410689), IO20 (DQ410675), IO21 (DQ410690), IO22 (DQ410691), IO23 (DQ410676), IO25 (DQ410692), IO26 (DQ410693), IO27 (DQ410694,) IO36 (DQ410677), IO37 (DQ410678), IO40 (DQ410679), IO41 (DQ410680), IO42 (DQ410681), IO43 (DQ410682), IO46 (DQ410683) and IO47 (DQ410695). The cyanophages S-WHM1 (AJ628769), S-PM2 (NC_006820), S-RSM2 (AJ628768), S-RSM28 (AJ629221), S-BM4 (AJ628858) and P-SSM4 (AY940168) along with the cyanobacteria Nostoc (NG_0037) and Synechocystis PCG6803 (NC_005229), Synechococcus strains WH7803, WH7805, RS9917, CC9605 (NC_007516), RS9917 and RGC307, Prochlorococcus strains MIT9313 (NC_005071) and MED4 (BX548174) were also included in the analysis.

Sequences from Synechococcus strains WH7803, WH7805, and RSS917 were kindly made available by D. Scanlan.

Sequences from Synechococcus strains WH7803 and RCC307 are available from http://www.genoscope.cns.fr/externe/English/ Projets/Projet_HP/organisme_HP.html. The tree is unrooted and was generated from nucleotide alignments of $292 \mathrm{nt}$. Clade support values above 65 are shown at the nodes of the clades. 
Table 1. Details of phage isolated in this study and included in the phylogenetic analysis of psb $\mathrm{D}$.

\begin{tabular}{lcc}
\hline Isolate & Time of isolation & Depth $(\mathrm{m})$ of isolation \\
\hline S-IO7 & 0100 & 10 \\
S-IO8 & 0100 & 10 \\
S-IO9 & 0100 & 10 \\
S-IO10 & 0100 & 10 \\
S-IO11 & 0100 & 10 \\
S-IO12 & 0100 & 10 \\
S-IO13 & 0100 & 10 \\
S-IO14 & 0100 & 10 \\
S-IO15 & 0100 & 10 \\
S-IO16 & 0700 & 10 \\
S-IO17 & 0700 & 10 \\
S-IO18 & 0700 & 10 \\
S-IO20 & 0700 & 10 \\
S-IO21 & 0700 & 10 \\
S-IO22 & 0700 & 10 \\
S-IO23 & 0700 & 10 \\
S-IO25 & 0700 & 10 \\
S-IO26 & 0700 & 10 \\
S-IO27 & 0700 & 25 \\
S-IO36 & 1900 & 25 \\
S-IO37 & 0100 & 25 \\
S-IO40 & 0700 & 25 \\
S-IO41 & 0700 & 25 \\
S-IO42 & 0700 & 25 \\
S-IO43 & 1300 & 50 \\
S-IO46 & 0100 & 50 \\
S-IO47 & 0100 & \\
\hline
\end{tabular}

encoded genes are only expressed at low levels in the dark (Gill et al., 2002), and the phages have acquired these genes, it seems likely that infection occurs in the daylight hours.

Several studies have used epifluorescence techniques to count viral abundance over short time scales (Jiang \& Paul, 1994; Weinbauer et al., 1995; GuixaBoixereu et al., 1999). The studies disagree with each other as to when viral abundance reaches a maximum (Bettarel et al., 2002). One of the most comprehensive surveys of marine microbial communities was carried out by Bettarel who showed that natural viral abundance peaked at around $1800 \mathrm{~h}$ (Bettarel et al., 2002). The correlation between Synechococcus and viral abundance, led the authors to suggest that virus-induced mortality is important in maintaining constant Synechococcus abundance. The authors suggest that these observations should be confirmed either by virus production studies or by the determination of infection rates.

The study described here takes a complementary approach to the previous work because, instead of staining and counting all viruses, phages which specifically infect Synechococcus were enumerated by isolation on hosts. In previous studies bacteriophages which infect heterotrophic bacteria could not be distinguished from those which infect cyanobacteria. No studies to date have enumerated Synechococcus phages from natural marine samples over short-term timescales. Results are presented for one complete $24 \mathrm{~h}$ period (5 time points). The objectives were twofold: (1) to quantify the number of infectious phages at specific time points; and (2) to observe the molecular diversity of the phages isolated at different depths over a short-timescale. We were interested to observe whether phages isolated from deeper depths represented a specific sub-community.

The Synechococcus host used in this study was WH7803. Although this strain was originally isolated in the Atlantic off Woods Hole, previous studies have shown it to be particularly amenable to phage infection from a range of geographical locations (Wilson et al., 1993; Marston \& Sallee, 2003; Millard \& Mann, 2006). This supports our case for using a single strain on which to enumerate phages. Water samples were collected throughout one 24-h period over a depth profile from an oligotrophic region of the Indian Ocean. The photosynthetic psbD gene encoding the $\mathrm{D} 2$ protein was used to determine the molecular diversity. Previous studies have shown the efficacy of this gene as a molecular marker (Lindell et al., 2004; Millard et al., 2004).

\section{MATERIALS AND METHODS}

\section{Host strains and medium}

Synechococcus sp. WH7803 was maintained in artificial seawater (ASW) medium in $100 \mathrm{ml}$ batch cultures in $250 \mathrm{ml}$ conical flasks under constant illumination (5-36 $\mu$ Einstein $\mathrm{m}^{-2} \mathrm{~s}^{-1}$ ) at $25^{\circ} \mathrm{C}$. One litre volumes were cultured in glass vessels to which $0.5 \mathrm{~g} \mathrm{l}^{-1}$ of $\mathrm{NaHCO}_{3}$ was added. Cultures were aerated and stirred constantly.

\section{Location and sampling}

A total of 30 water samples were kindly collected from one sampling site from the Indian Ocean by N. Fuller and K. Orcutt (both previously at the University of Warwick, the latter now at the University of Maine, USA). Samples were taken from a station at $03^{\circ} 48^{\prime} \mathrm{N} 67^{\circ} 00^{\prime} \mathrm{E}$; water samples were taken at 1300 and $1900 \mathrm{~h}$ local time on 7 September 2001 and 0100, 0700 and $1300 \mathrm{~h} \mathrm{local}$ time on 8 September 2001 at depths of $10 \mathrm{~m}, 25 \mathrm{~m}, 50 \mathrm{~m}$, $80 \mathrm{~m}, 100 \mathrm{~m}$ and $130 \mathrm{~m}$. Water samples were passed through a filter with a $0.2 \mu \mathrm{m}$ pore size and stored in the dark at $4^{\circ} \mathrm{C}$ until they were used. The water samples were stored at $4^{\circ} \mathrm{C}$ for four years. It has been shown that phages can survive at this temperature for at least $28 \mathrm{y}$ (Ackermann, in press). There is also no reason to suggest that viral decay would be different from samples collected at different depths.

\section{Estimation of cyanophage abundance and phage isolation}

Cyanophage abundance was determined by performing direct double-agar-layer plaque assays on Synechococcus sp. WH7803. A minimum of three replicates was used to enumerate cyanophage numbers for all 30 water samples. As has been previously described, specific cyanophages were isolated by the removal of a plaque from the Petri dish with a Pasteur pipette (Wilson et al., 1993). Plaques were then resuspended in $1 \mathrm{ml}$ of ASW, and used in two further rounds of plaque assay purification. Isolates were named following the previously 

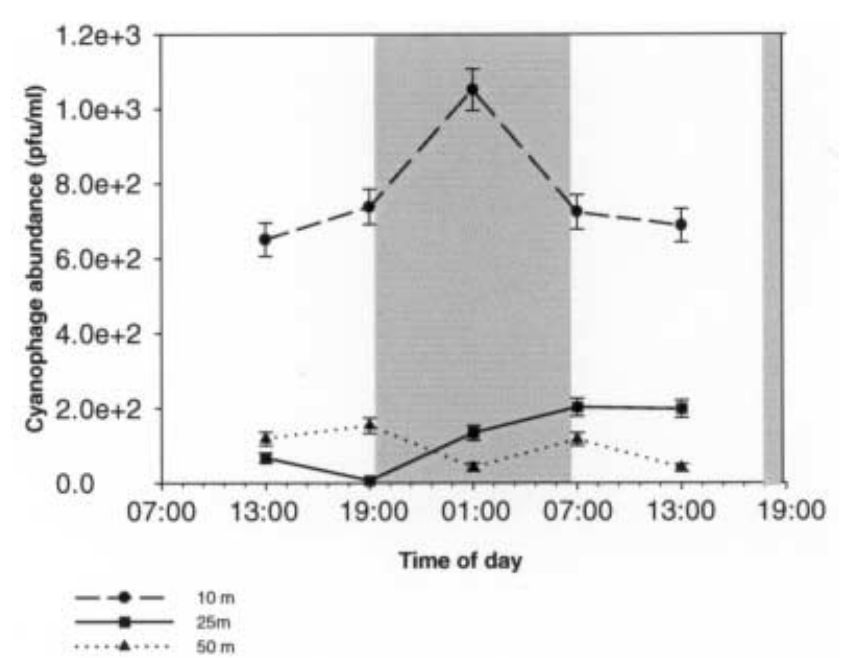

Figure 2. Cyanophage abundance over time from a station at $19^{\circ} 00^{\prime} \mathrm{N} 67^{\circ} 00^{\prime} \mathrm{E}$ in the Indian Ocean, from 1300 on 7 September 2001 until 1300 on 8 September 2001. Cyanophage abundance was determined using Synechococcus WH7803 as host. The grey shaded areas indicate the periods of darkness. No phages were detected at depths lower than $50 \mathrm{~m}$. Error bars represent standard deviation.

suggested convention of Suttle (Suttle, 2000b) using the letters IO to represent the Indian Ocean as the place of isolation.

\section{DNA extraction}

DNA was extracted from confluently-lysed plates of clonal cyanophage isolates. The top agar from two or more $85 \mathrm{~mm}$ diameter plates was pooled and resuspended in $2 \mathrm{ml}$ of ASW (approximately $1 \mathrm{ml} \mathrm{ASW}$ per plate was required). DNA was then extracted as previously described (e.g. Wilson et al., 1993); briefly, a phenol extraction was followed by a phenol/chloroform (1:1) extraction and an iso-amyl alcohol/chloroform (1:24) extraction. DNA was then precipitated with ammonium acetate at a final concentration of $0.5 \mathrm{M}$ in 2 volumes of propan-2-ol, before being washed in $70 \%$ ethanol and resuspended in $50 \mu \mathrm{l}$ of $\mathrm{H}_{2} 0$.

\section{Primer design and PCR amplification}

The $p s b D$ sequence from cyanophages S-BM4, S-RSM88， SWHM1， S-RSM2， S-RSM28， P-SSM4 (accession numbers AJ628858 AJ629075 AJ628769 AJ628768 AJ629221 and AY940168 respectively) were aligned using CLUSTALX (Thompson et al., 1997). Primers were designed manually against conserved regions. The primers $p s b D F$ $\left(5^{\prime}\right.$-GGNTTYATGCTNMGNCARTT-3') and psbDR (5'-CKRTTNGGNGTVAYGAT-3') amplify a 383 bp product. The reaction mixture contained $10 \mathrm{ng}$ of template DNA, $200 \mu \mathrm{M} \quad \mathrm{dNTPs}, \quad 3 \mathrm{mM} \quad \mathrm{MgCl}_{2}$, $50 \mathrm{nM}$ primers ( $p s b D F$ and $p s b D R$ ), 1.5 units of Taq polymerase (Invitrogen), and $1 \times$ enzyme buffer $(50 \mathrm{mM}$ Tris $-\mathrm{HCl}$, $100 \mathrm{mM} \mathrm{NaCl}, 0.15 \mathrm{mM} \mathrm{MgCl}_{2}$ ) with water to a final volume of $50 \mu \mathrm{l}$. The polymerase chain reaction (PCR) amplification was carried out in a DNA thermal cycler
( $\mathrm{T}$ gradient), and reactions were conducted using the following amplification conditions: an initial denaturation step of $94^{\circ} \mathrm{C}$ for $2 \mathrm{~min}$, followed by ten cycles of denaturation at $94^{\circ} \mathrm{C}$ for $30 \mathrm{~s}$, annealing at $45^{\circ} \mathrm{C}\left(-1^{\circ} \mathrm{C}\right.$ per cycle) for $30 \mathrm{~s}$, and elongation at $72^{\circ} \mathrm{C}$ for $30 \mathrm{~s}$. This was followed by 25 cycles of $94^{\circ} \mathrm{C}$ for $30 \mathrm{~s}, 35^{\circ} \mathrm{C}$ for $30 \mathrm{~s}$, and $72^{\circ} \mathrm{C}$ for $30 \mathrm{~s}$. The final extension was at $72^{\circ} \mathrm{C}$ for $1 \mathrm{~min}$ held at $4^{\circ} \mathrm{C}$. The PCR products were purified using a Qiagen gel extraction kit. Sequencing was carried out using $\sim 200 \mathrm{ng}$ of template with 5.5 pmoles of primer using the Big Dye version 3.1 chemistry (ABI) and analysed on an ABI Prism 3100 sequencer. To ensure $2 \times$ coverage of the PCR product, both $p s b D F$ and $p s b D R$ primers were used to sequence the PCR product.

\section{Phylogenetic analysis}

The cyanophage $p s b D$ sequences were aligned using CLUSTALX and corrected and edited manually as necessary. The analyses was performed in MRBAYES using the GTR model. 500,000 iterations were used with a sample frequency of every 1000 with a burn-in after 250 (Huelsenbeck \& Renquist, 2001). Analyses were also performed using both neighbour joining and maximum parsimony analysis in PAUP* (Swofford, 1998). For nucleotide alignments, any gaps in the data matrix were treated as missing data.

\section{RESULTS AND DISCUSSION}

\section{Cyanophage abundance over a short-term cycle}

Picophytoplankton are the most abundant primary producers in the Indian Ocean and two groups of cyanobacteria, Prochlorococcus and Synechococcus, dominate the assemblage. Cyanophage isolates were obtained from a single location in the Indian Ocean. The short-term variability of the phage population was monitored at six depths every $6 \mathrm{~h}$ for a $24 \mathrm{~h}$ period. Cyanophage abundance in seawater samples was determined by counting the number of plaque forming units (pfu) per ml of seawater. The phages were isolated on plates and as expected, plaques were evident after around $10 \mathrm{~d}$ of incubation. Cyanophages were most abundant in seawater samples obtained from a depth of $10 \mathrm{~m}$. Phages were present but in much smaller numbers at $25 \mathrm{~m}$ and $50 \mathrm{~m}$, and no phages were found below $50 \mathrm{~m}$. Thus no phages were isolated from water at $80 \mathrm{~m}, 100 \mathrm{~m}$ or $130 \mathrm{~m}$. Unfortunately, Synechococcus flow cytometry data are not available for every time point that water was collected for phage isolation. One data set for the Synechococcus numbers was collected during the sample period and cell numbers per $\mathrm{ml}$ were as follows: $10 \mathrm{~m}$ (5314), $25 \mathrm{~m} \mathrm{(5304),} \mathrm{and} 55 \mathrm{~m}$ (9465), $75 \mathrm{~m}$ (1733), $110 \mathrm{~m} \mathrm{(21)} \mathrm{and} 215 \mathrm{~m} \mathrm{(0).}$

The number of phages isolated from $10 \mathrm{~m}$ exhibited strong short-term variability with the highest number of phages found at $0100 \mathrm{~h}$ (Figure 1). This suggests that $0100 \mathrm{~h}$ represents favourable conditions for viral release and/or reduced viral decay. At either side of this $0100 \mathrm{~h}$ peak approximately $6 \times 10^{2}$ pfu $\mathrm{ml}^{-1}$ were counted whereas almost twice as many pfu (approximately $1 \times 10^{3}$ pfu $\mathrm{ml}^{-1}$ ) were detected at $0100 \mathrm{~h}$. These data are consistent with the hypothetical situation presented by Winter et al. (2002) who suggested that the maximal viral activity 
occurs during the most metabolically-active periods of cell growth. Cyanobacteria are more active during daylight hours and thus viral infection may start with the onset of dawn and replication may proceed during the day where enough light is provided for photosynthetic energy production. Indeed, it has been suggested that replication of viral DNA is delayed until light (and thus enough energy) is available (Thyrhaug et al., 2002). Therefore, we extend the hypothesis presented by Winter et al. (2002) by suggesting that, during the night, the number of phage available for potential interaction with Synechococcus is at a maximum. At dawn the infection cycle begins and continues throughout the daylight hours. This is not inconsistent with the $1800 \mathrm{~h}$ peak observed by Bettarel et al. (2002) as that study would have counted both phages from cyanobacteria and those that infect heterotrophic bacteria.

The bacteriophage latent period has been shown to be related to the host density (Abedon et al., 2001). The oceanic bacterial composition is complicated with bacteria being present at a range of abundances. Both cyanobacteria and heterotrophic bacteria are thought to be present at roughly equal parity, each at concentrations of up to $10^{6} \mathrm{ml}^{-1}$ (Wommack \& Colwell, 2000). The range of bacterial abundances leads to a complicated dynamic and thus the $1800 \mathrm{~h}$ peak observed by Bettarel et al. (2002) may represent phages from abundant heterotrophic bacteria with shorter latent periods. Under laboratory conditions cyanophages appear to have longer latent periods than phages which infect heterotrophic bacteria (Wilson et al., 1993; Miller et al., 2003). Therefore the peak which we observed at $0100 \mathrm{~h}$ may represent viral release from the most abundant cyanobacteria.

Further support for the idea of phage infecting cells at the onset of day comes from unpublished work in this laboratory and from Curtis Suttle (personal communication) that has shown that some Synechococcus phages can only bind to cells in the presence of light and in conditions of darkness no absorption will occur. We have found that under laboratory conditions, it takes around $9 \mathrm{~h}$ for a 'typical' Synechococcus phage to go from infection to lysis (the latent period) (Clokie et al., 2006). This was established under laboratory conditions where cells were grown in an excess of nutrients. We have limited data on how high nutrient starvation influences latent periods; however, it is known that when Synechococcus is grown under conditions of nutrient starvation, the latent period is extended (Wilson et al., 1996). Secondly, the interaction between Synechococcus and phages is stochastic such that there is no such event whereby dawn is followed by an immediate simultaneous infection of all Synechococcus. Therefore, throughout the day Synechococcus cells will be infected and the infection cycle will culminate in lysis at some point several hours later. These newly released phages will be susceptible to light damage until after sunset. The explanation for the maximum peak of virus abundance at $0100 \mathrm{~h}$ therefore is likely to represent stochastic infection, long latent periods and reduced viral decay.

Less obvious variation is observed at $25 \mathrm{~m}$ and at $50 \mathrm{~m}$, and the number of pfu counted is much lower at these depths (Figure 1). It seems that the likely explanation for the fact that no phages were isolated from depths of
$80 \mathrm{~m}$ or below is that Synechococcus cell numbers were very low. However, at depths of $25 \mathrm{~m}$ and $50 \mathrm{~m}$ Synechococcus numbers are still high and yet fewer phages were isolated at these depths than at $10 \mathrm{~m}$ which had comparable Synechococcus numbers. There are two possible explanations as to why this is the case. The first is that Synechococcus WH7803 is more resistant to the phages naturally occurring with these depths. It has been shown that Synechococcus hosts can naturally occur with their phages and thus must be resistant to infection (Waterbury \& Valois, 1993). The second explanation is that high phage numbers reflect recent lysis events and thus more lysis may be happening in the upper layers. In the water samples collected from $25 \mathrm{~m}$, the maximum number of phages was observed at $0700 \mathrm{~h}$. This is discussed below in the context of psbD diversity. For the samples collected at $50 \mathrm{~m}$, the highest numbers of pfu were observed at $1900 \mathrm{~h}$ (Figure 1).

The lack of diurnal variation in deeper waters may be explained by the fact that the solar radiance is not as strong at these depths as it is at $10 \mathrm{~m}$. Light attenuation is caused by the combined absorption and scattering properties of everything in the water column, including the water itself. Beer's law states that light decreases exponentially with depth such that $I_{z}=I_{0} * \exp ^{-k^{*}}$ (where $I_{z}=$ intensity of light at depth $\mathrm{z} ; \mathrm{I}_{0}=$ intensity of light at depth zero; $\mathrm{k}=$ attenuation coefficient) (Clark, 1995). Thus differences of radiation intensity that occur in the surface waters are not apparent when dealing with water at $50 \mathrm{~m}$.

The reason for the lack of isolation-based studies is probably due to the work being very labour intensive, time-consuming and difficult to do in situ, as it requires large amounts of exponentially growing Synechococcus. Although these results confirm and extend results from studies based on epifluorescence and counting techniques, they need to be extended by the isolation of phages from further diel cycles. This study has at least shown that shortterm fluctuations in cyanophage numbers do occur. This abundance-based data set reveals the complexity of shortterm changes in cyanophages of the surface waters, but the lack of such an obvious pattern in deeper waters.

\section{Cyanophage isolation}

As well as the enumeration of cyanophage abundance over a diel cycle, 50 individual phages were isolated and purified. The overwhelming majority of cyanophages which have been isolated are from the family Myoviridae (Wilson et al., 1993; Sullivan et al., 2003; McDaniel et al., 2006; Millard \& Mann, 2006), and there is no reason to suggest that phages isolated in this study should be any different. If so, their names would reflect this and be S-IOM1-S-IOM50. Family affiliation needs to be confirmed using transmission electron microscopy studies and as these studies have not yet been carried out we cannot unequivocally say these viruses are myoviruses so we have named them S-IO1-S-IO50.

\section{Molecular diversity of cyanophages}

A section of the $p s b D$ gene from 27 of the 50 cyanophages isolated was sequenced. This gene was chosen for analysis as previous work had shown that it was a better phylogenetic marker than the other phage-encoded 
photosynthesis gene $p s b A$ (Millard et al., 2004). Interestingly, all of the phages isolated in this study that were tested (27 phages see Table 1), proved positive for the $p s b D$ gene.

Light intensity and wavelength are suggested to have an impact on the distribution patterns of photoautotrophs in the marine environment (Olson et al., 1990; Wilhelm et al., 1998). It seems likely that the distribution patterns of the photoautotrophs are reflected by niche-specific distribution patterns of viruses. It was of great interest therefore to ascertain whether phages isolated from deeper waters would cluster together in a phylogenetic analysis and this does not appear to be the case (Figure 2 ). Regardless of whether the phylogenetic analyses were performed using neighbour joining, maximum parsimony or a Bayesian analysis, the same patterns of relationship were apparent. Both of the phages isolated from $50 \mathrm{~m}$ (S-IO46 and $\mathrm{S}-\mathrm{IO} 47$ ) are in the same group as phages isolated at $10 \mathrm{~m}$. However, two of the other phages isolated from $25 \mathrm{~m}$ (S-IO42 and S-IO43) cluster together (this holds true for all analyses). The remaining two phages isolated from $25 \mathrm{~m}$ (S-IO36 and S-IO40) group together but again this group includes other phages isolated from $10 \mathrm{~m}$. From the limited sample size it appears that there is no clear pattern, but it would seem possible that some phages from deeper waters form distinct groups.

The phylogenetic analysis revealed several other interesting observations. All of the phages included in the analysis, with the exception of S-PM2, fall within a distinct group with $100 \%$ bootstrap support. Most of the Indian Ocean phages form a discrete group within this main group with a bootstrap support of $99 \%$. None of the phages isolated from other locations fall within this group. The majority of the Indian Ocean phages are unresolved within this large group however, which is suggestive of a relatively recent radiation. There appeared to be no clades containing phages isolated at a particular time point. Although the Synechococcus phages appear to be more closely related to the Prochlorococcus strain MED4 than to Synechococcus strains, this is likely to be due to homoplasy rather than homology due to the high AT content in the genomes of both high-light Prochlorococcus strains and in all cyanophage genomes.

In summary, this study is the first of its kind in terms of taking an isolation based approach to enumerate specific phages infecting the Synechococcus component of the microbial community over such short timescales. Unsurprisingly, phages are most abundant in surface waters and there is a pronounced increase in phage numbers at $0100 \mathrm{~h}$. This possibly reflects an increase in phage release at this time which makes sense in terms of our knowledge of infection behaviour, timescales and latent periods. The study of the diversity of $p s b D$ genes has provided a preliminary insight into the structure of the phage community. Extended studies of this type should give a valuable insight into this complex, but fascinating, dynamic.

This work was part funded by Natural Environment Research Council grants awarded to N.H. Mann. We gratefully thank N. Fuller and K. Orcutt for the collection of water samples from the Indian Ocean that were used in this study. These samples were taken as part of the RRS 'Charles Darwin Ambition' cruise that took place from 30 August to 29 September, 2001. Sequences kindly made available by D. Scanlan were part of the sequencing project of the Moore Foundation.

\section{REFERENCES}

Abedon, S.T., Herschler, T.D. \& Stopar, D., 2001. Bacteriophage latent-period evolution as a response to resource availability. Applied and Environmental Microbiology, 67, 4233-4241.

Ackermann, H., in press. The characterization and taxonomy of phages. In Bacteriophages: methods and protocols (ed. M.R.J. Clokie and A. Kropinski). Totowa, New Jersey: Humana Scientific Press.

Bailey, S., Thompson, E., Nixon, P.J., Horton, P., Mullineaux, G.W., Robinson, C. \& Mann, N.H., 2002. A critical role for the Var2 FtsH homologue of Arabidopsis thaliana in the photosystem II repair cycle in vivo. Fournal of Biological Chemistry, 277, 2006-2011.

Bergh, O., Borsheim, K.Y., Bratbak, G. \& Heldal, M., 1989. High abundance of viruses found in aquatic environments. Nature, London, 340, 467-468.

Bettarel, Y. et al., 2002. Strong, weak, and missing links in a microbial community of the N.W. Mediterranean Sea. FEMS Microbiology Ecology, 42, 451-462.

Clark, N.R., 1995. Reflectance spectra: rock physics and phase reflections, a handbook of physical constants. Washington DC: American Geophysical Union.

Clokie, M.R.J., Shan, J., Bailey, S., Jia, Y., Krisch, H.M., West, S. \& Mann, N.H., 2006. Transcription of a 'photosynthetic' T4type phage that infects marine cyanobacteria. Environmental Microbiology, in press.

Gill, R.T., Katsoulakis, E., Schmitt, W., Taroncher-Oldenburg, G., Misra, J. \& Stephanopoulos, G., 2002. Genome-wide dynamic transcriptional profiling of the light-to-dark transition in Synechocystis sp. strain PCG 6803. Fournal of Bacteriology, 184, 3671-3681.

Goericke, R. \& Welschmeyer, N.A., 1993. The marine prochlorophyte Prochlorococcus contributes significantly to phytoplankton biomass and primary production in the Sargasso Sea. Deep-Sea Research I, 40, 2283-2294.

GuixaBoixereu, N., Lysnes, K. \& PedrosAlio, C., 1999. Viral lysis and bacterivory during a phytoplankton bloom water microcosm. Applied and Environmental Microbiology, 65, 1949-1958.

Huelsenbeck, J.P. \& Ronquist, F., 2001. MRBAYES: Bayesian inference of phylogeny. Bioinformatics, 17, 754-755.

Jiang, S.C. \& Paul, J.H., 1994. Seasonal and diel abundance of viruses and occurrence of lysogeny/bacteriocinogeny in the marine environment. Marine Ecology Progress Series, 94, 163-172.

Lindell, D., Sullivan, M.B., Johnson, Z.I., Tolonen, A.C., Rohwer, F. \& Chisholm, S.W., 2004. Transfer of photosynthesis genes to and from Prochlorococcus viruses. Proceedings of the National Academy of Sciences of the United States of America, 101, 11013-11018.

Liu, H.B., Nolla, H.A. \& Campbell, L., 1997. Prochlorococcus growth rate and contribution to primary production in the equatorial and subtropical North Pacific Ocean. Aquatic Microbial Ecology, 12, 39-47.

Mann, N.H., 2003. Phages of the marine cyanobacterial picophytoplankton. FEMS Microbiology Reviewes, 27, 17-34.

Mann, N.H., Clokie, M.R.J., Millard, A., Cook, A., Wilson, W.H., Wheatley, P.J., Letarov, A. \& Krisch, H.M., 2005. The genome of S-PM2, a 'photosynthetic' T4-type bacteriophage that infects marine Synechococcus strains. Fournal of Bacteriology, 187, 3188-3200.

Marston, M.F. \& Sallee, J.L., 2003. Genetic diversity and temporal variation in the cyanophage community infecting marine Synechococcus species in Rhode Island coastal waters. Applied and Environmental Microbiology, 69, 4639-4647. 
McDaniel, L.D., delaRosa, M. \& Paul, J.H., 2006. Temperate and lytic cyanophages from the Gulf of Mexico. Fournal of the Marine Biological Association of the United Kingdom, 86, 517-527.

Millard, A., Clokie, M.R.J., Shub, D.A. \& Mann, N.H., 2004. Genetic organization of the $p s b A D$ region in phages infecting marine Synechococcus strains. Proceedings of the National Academy of Sciences of the United States of America, 101, 11007-11012.

Millard, A.D. \& Mann, N.H., 2006. A temporal and spatial investigation of cyanophage abundance in the Gulf of Aqaba, Red Sea. Fournal of the Marine Biological Association of the United Kingdom, 86, 507-515.

Miller, E.S., Kutter, E., Mosig, G., Arisaka, F., Kunisawa, T. \& Rüger, W., 2003. Bacteriophage T4 genome. Microbiology and Molecular Biology Reviews, 67, 86-156.

Mühling, M. et al., 2005. Genetic diversity of marine Synechococcus and co-occurring cyanophage communities: evidence for viral control of phytoplankton. Environmental Microbiology, 7, 499-508.

Olson, R.J., Chisholm, S.W., Zettler, E.R., Altabet, M.A. \& Dusenberry, J.A., 1990. Spatial and temporal distributions of prochlorophyte picoplankton in the North Atlantic Ocean. Deep-Sea Research Part A: Oceanographic Research Papers, 37, 10331051.

Sullivan, M.B., Waterbury, J.B. \& Chisholm, S.W., 2003. Cyanophages infecting the oceanic cyanobacterium Prochlorococcus. Nature, London, 424, 1047-1051.

Suttle, C.A., 2000a. Gyanophages and their role in the ecology of cyanobacteria. In The ecology of cyanobacteria: their diversity in time and space (ed. P.M. Whitton), 563-589. Boston: Kluwer Academic Publishers.

Suttle, C.A., 2000b. The ecological, evolutionary and geochemical consequences of viral infection of cyanobacteria and eukaryotic algae. In Viral ecology (ed. C.J. Hurst), pp. 248-286. London: Academic Press.

Swofford, D.L., 1998. PAUP* Phylogenetic analysis using parsimony (and other methods). Sunderland, MA: Sinauer.

Thompson, J.D., Gibson, T.J., Plewniak, F., Jeanmougin, F. \& Higgins, D.G., 1997. The ClustalX windows interface: flexible strategies for multiple sequence alignment aided by quality analysis tools. Nucleic Acids Research, 24, 4876-4882.
Thyrhaug, R., Larsen, A., Brussaard, C. \& Bratbak, G., 2002. Cell cycle dependent virus production in marine phytoplankton. Journal of Phycology, 38, 338-343.

Waterbury, J.B. \& Valois, F.W., 1993. Resistance to co-occurring phages enables marine Synechococcus communities to coexist with cyanophages abundant in seawater. Applied and Environmental Microbiology, 59, 3393-3399.

Weinbauer, M.G., Fuks, D., Puskaric, S. \& Peduzzi, P., 1995. Diel, seasonal, and depth-related variability of viruses dissolved DNA in the Northern Adriatic Sea. Microbial Ecology, 30, 25-41.

Weinbauer, M.G. \& Rassoulzadegan, F., 2004. Are viruses driving microbial diversification and diversity? Environmental Microbiology, 6, 1-11.

Wilhelm, S.W., Weinbauer, M.G., Suttle, G.A., Pledger, R.J. \& Mitchell, D.L., 1998. Measurements of DNA damage and photoreactivation imply viruses in marine surface waters are infective. Aquatic Microbial Ecology, 14, 215-222.

Wilson, W.H., Carr, N.G. \& Mann, N.H., 1996. The effect of phosphate status on the kinetics of cyanophage infection in the oceanic cyanobacterium Synechococcus sp. WH7803. Fournal of Phycology, 32, 506-516.

Wilson, W.H., Joint, I.R., Carr, N.G. \& Mann, N.H., 1993. Isolation and molecular characterization of 5 marine cyanophages propagated on Synechococcus sp. strain WH7803. Applied and Environmental Microbiology, 59, 3736-3743.

Winter, C., Herndl, G.J. \& Weinbauer, M.G., 2004. Diel cycles in viral infection of bacterioplankton in the North Sea. Aquatic Microbial Ecology, 35, 207-216.

Wommack, K.E. \& Colwell, R.R., 2000. Virioplankton: viruses in aquatic ecosystems. Microbiology and Molecular Biology Reviews, 64, 69-114. 